\title{
EFFECTS OF GEOMETRIC PARAMETERS ON MEAN WIND PRESSURE ON GABLE ROOFS OF LOW-RISE BUILDINGS
}

\author{
Y. Quan ${ }^{1, *}$, Y. Tamura ${ }^{2}$ and M. Matsui ${ }^{3}$ \\ ${ }^{1}$ COE Researcher, Department of Architecture, Tokyo Polytechnic University, Japan \\ *(Corresponding author: E-mail: quanyong@arch.t-kougei.ac.jp) \\ ${ }_{2}^{2}$ Professor, Department of Architecture, Tokyo Polytechnic University, Japan \\ ${ }^{3}$ Associate Professor, Department of Architecture, Tokyo Polytechnic University, Japan
}

Received: 29 March 2006; Revised: 27 June 2006; Accepted: 3 July 2006

\begin{abstract}
A series of pressure measurement wind tunnel tests were carried out on low-rise buildings in a simulated suburban wind field. The effects of roof pitch, height/breadth ratio and depth/breadth ratio of gable-roofed low-rise buildings on mean wind pressure coefficients on their roofs for winds parallel or perpendicular to the ridges were discussed. Two new equations of mean wind pressure coefficients, which may be useful for design purpose, were fitted with the test data for various building shapes and the errors of those equations were analyzed carefully. The calculated results with the equations were compared with present wind tunnel test data and literature in detail.
\end{abstract}

Keywords: low-rise building, gable roof, wind load, wind pressure, wind tunnel test, fitted equation

\section{INTRODUCTION}

The majority of structural damage in windstorms has been incurred by low-rise buildings, especially family dwellings that were non-engineered and lacking in maintenance (Homes [1]). For example, Typhoon No. 19 in 1991 (Typhoon 9119) caused severe damage to low-rise buildings over almost all of Japan. The insurance payout for losses caused by this typhoon reached 567.5 billion yen, which at that time was the largest in the world for losses caused by a natural disaster. According to a damage investigation, most wind damage to low-rise buildings was restricted to their envelopes, and in particular to the roof sheathing. This indicates that improvement in the wind resistance to building envelopes can result in a significant reduction in overall economic losses (Uematsu [2]).

Over the last twenty years, a lot of research has been carried out on wind loads on low-rise buildings with gable roofs. Stathopolous [3] and Stathopolous, Surry and Davenport [4] carried out an exhaustive parametric study on wind pressure that led to North American codification. The work by Holmes [5] and other studies reported by Holmes [6] provided the basis for the Australian codification. The studies of Kamei \& Maruta [7], Ueda, Tamura and Fujii [8] and Maruta et al. [9] improved the Japanese standard [10]. With the appearance of more and more wind tunnel test data and full-scale measurement data, load standards have been continually revised. In order to make them easy to use for engineers, load standards often provide a simple calculating method that can yield wind loads in most practical cases. However, the calculated results given by such simple calculating methods are often not very precise. For example, most standards offer a single mean wind pressure coefficient for the whole windward gable roof of a building for wind flowing across the roof ridge, where in fact the mean wind pressure coefficient varies with location. The values near the eaves are often much larger than those at other locations, as shown in Figure 4.

In order to make a wind-load database of low-rise buildings, a series of wind pressure measurement wind tunnel tests have been carried out on low-rise buildings in the Atmospheric Boundary Wind Tunnel in the Tokyo Polytechnic University. Contours of average, maximum, minimum and RMS values of the wind pressure coefficients on the roof and walls of such buildings have then been 
drawn using this wind tunnel test data, which were disclosed on the website of the Wind Engineering Research Center, Tokyo Polytechnic University (http://www.wind.arch.t-kougei.ac.jp/ info_center/weic.html). Based on those test data, the present study attempts to obtain relatively simple and precise equations of mean wind pressure coefficients on gable roofs of low-rise buildings with different geometric parameters.

\section{PRESSURE MEASUREMENT WIND TUNNEL TESTS}

Pressure measurement wind tunnel tests on low-rise buildings were executed in the Boundary Layer Wind Tunnel, $2.2 \mathrm{~m}$ wide by $1.8 \mathrm{~m}$ high, in the Tokyo Polytechnic University, Japan. The length scale, velocity scale and time scale are 1/50,1/5 and 1/10, respectively.

\subsection{Wind Field}

Since a lot of low-rise buildings are located in suburban areas, the suburban terrain corresponding to terrain categories III in AIJ [10] is chose as the tested wind field. It is simulated with turbulence generating spires, roughness elements and a carpet arranged on the upstream floor of the test section. The exponent of the mean wind profiles of this simulated wind field is 0.20 and the turbulence intensity at the mean height of the roofs of most test models, about $150 \mathrm{~mm}$, is about 0.24 . The simulated result is shown in Figure 1.
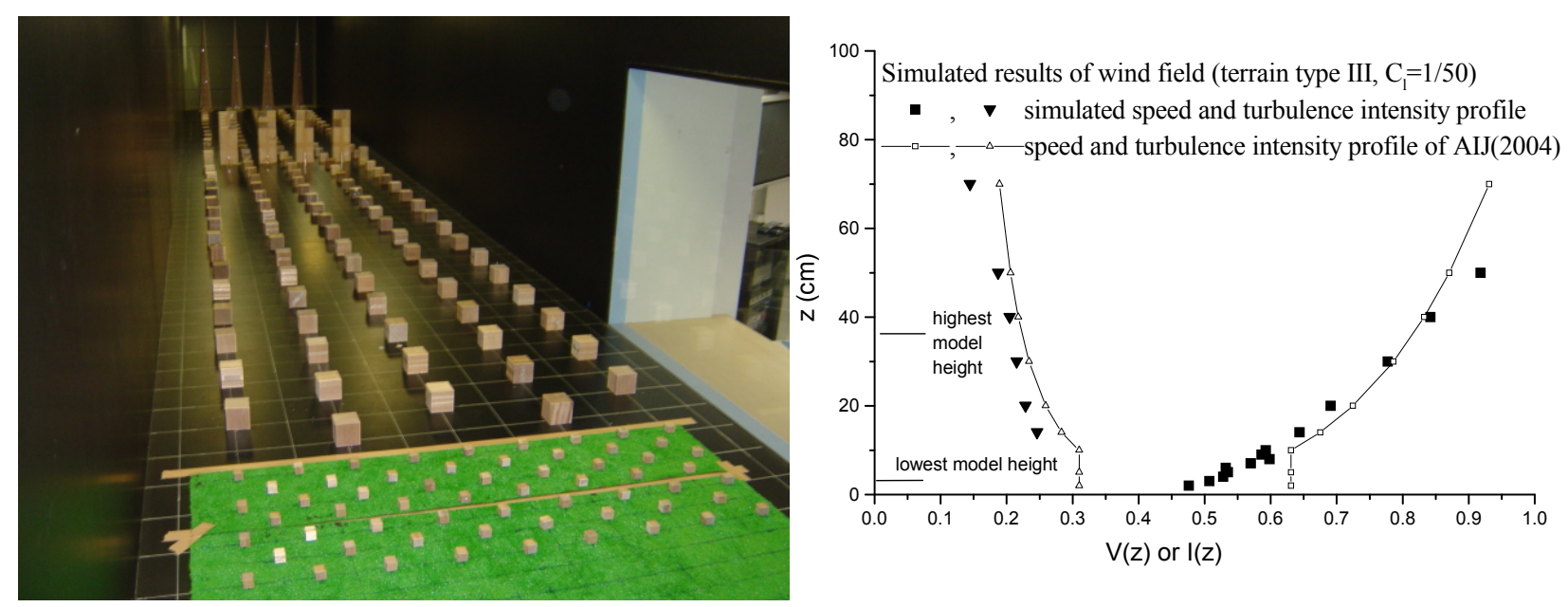

Figure 1. Simulated Wind Field

\section{$2.2 \quad$ Testing Models}

Figure 2 shows the test model of a gable house. H, B and D are height, breadth and depth, respectively. $\beta$ is roof pitch. $\theta$ is wind direction angle. When $\theta$ is zero degree, the wind flows along the roof ridge. In order to study the effects of the roof pitch, height/breadth ratio and depth/breadth ratio on wind pressure coefficients on the gable roof, 30 models of gable-roofed low-rise buildings with roof pitch of $0^{\circ} \sim 45^{\circ}$, heights/breadth ratio of 3/8 18/8 and depth/breadth ratio of $1 \sim 4$, as shown in Table 1 , were tested. The range of tested wind direction angles was $0^{\circ} \sim 90^{\circ}$ in increments of $15^{\circ}$. 

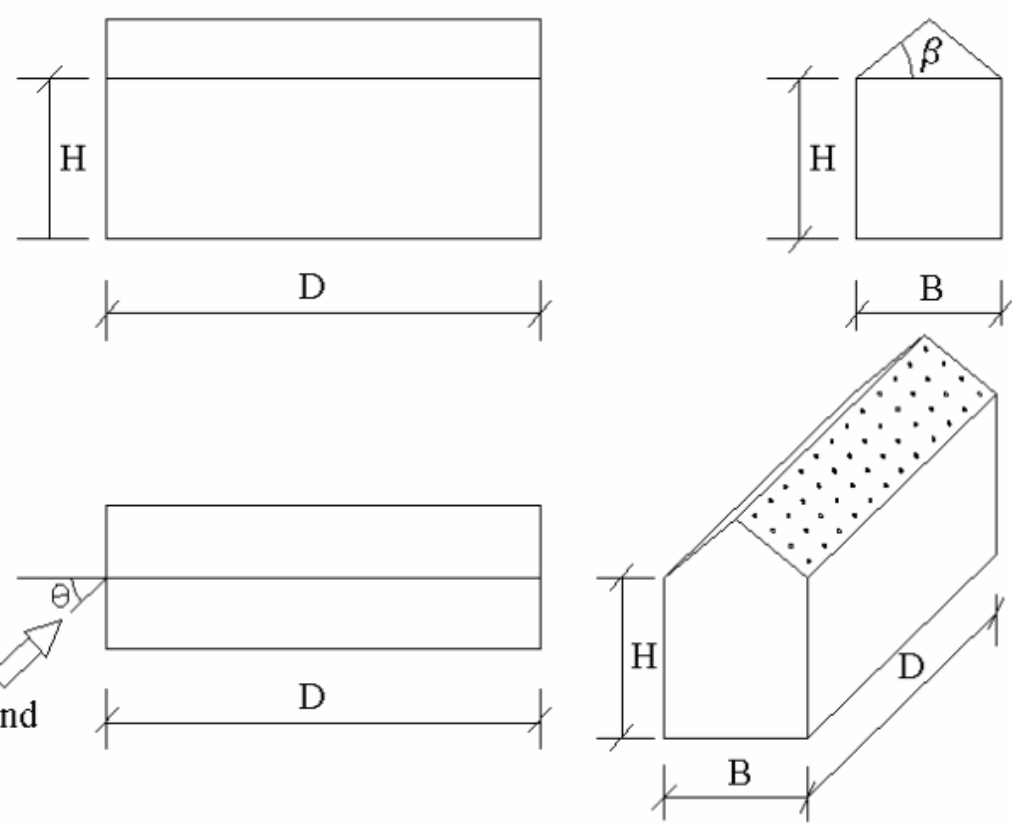

Figure 2. Test Model

Table 1. Parameters of Test Models of Gable-roofed Buildings (Length Unit: $\mathrm{cm}$ )

\begin{tabular}{|c|c|c|c|c|}
\hline No. & B & D & H & $\beta\left(^{\circ}\right)$ \\
\hline $1 \sim 6$ & 16 & 24 & $6,12,18,24,30,36$ & 26.7 \\
\hline $7 \sim 12$ & 16 & $16,32,40,48,56,64$ & 12 & 26.7 \\
\hline $13 \sim 18$ & 16 & 24 & 12 & $45,30,21.8,18.4,4.8,0$ \\
\hline $19 \sim 21$ & 16 & 24 & $3.2,6.4,16$ & 45 \\
\hline $22 \sim 24$ & 16 & 24 & $3.2,64,16$ & 26.7 \\
\hline $25 \sim 27$ & 16 & 24 & $3.2,64,16$ & 18.4 \\
\hline $28 \sim 30$ & 16 & 24 & $3.2,64,16$ & 4.8 \\
\hline
\end{tabular}

\subsection{Wind Pressure Measurement System}

Pressure taps were arranged on the roofs of the testing models at intervals of $20 \mathrm{~mm}$. All taps were connected to a pressure measurement scanner by tubes with a length of $1.2 \mathrm{~m}$ and an inner diameter of $0.8 \mathrm{~mm}$. The scanner could measure wind pressures on 384 points simultaneously. Wind pressures on all pressure taps were measured simultaneously with a sampling frequency of $800 \mathrm{~Hz}$ corresponding to $80 \mathrm{hz}$ in full scale and a sampling time of 60 seconds corresponding to $10 \mathrm{~min}$ in full scale. Each test case was sampled 10 times. The test data were low-pass filtered at $300 \mathrm{hz}$.

\subsection{Test Data Process}

The transfer function of the tube system as shown in Figure 3 is identified with frequency sweep method. The effect of the tube system on the measured wind pressure was eliminated by dividing the transfer function from the power spectra of the measured raw test data series. Before calculating the statistical values of the wind pressure, the test data were moving averaged every 80 points to make the duration of the peak and RMS value $1 \mathrm{~s}$ in full scale. 


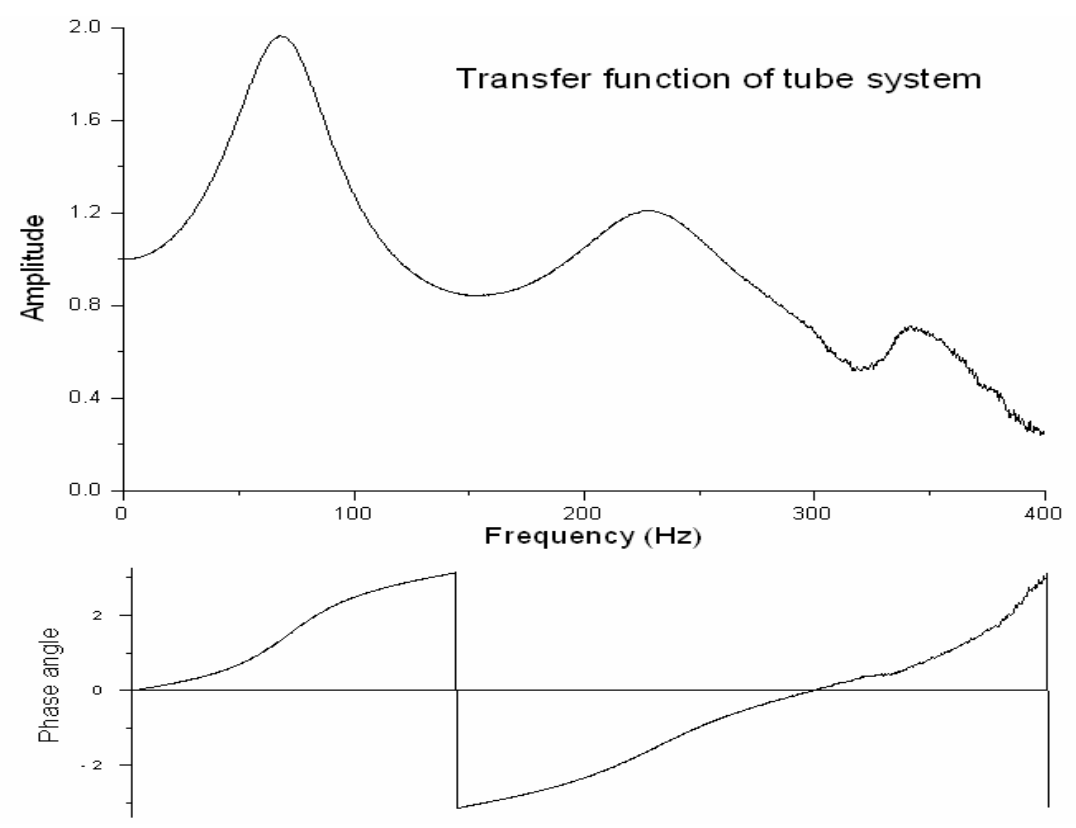

Figure 3. Transfer Function of Tube System

The statistical values of the wind pressures coefficients were the average of the statistical values of the 10 samples. They were calculated from the following equations:

$$
\begin{aligned}
& \bar{C}_{p}=\bar{p} / p_{H 0} \\
& \widehat{C}_{p}=\hat{p} / p_{H 0} \\
& \breve{C}_{p}=\breve{p} / p_{H 0} \\
& C_{p}^{\prime}=p^{\prime} / p_{H 0}
\end{aligned}
$$

where $p$ is local pressure; $p_{H 0}$ is the reference pressure of the approach wind the average roof height, $H 0=H+\tan \beta \cdot B / 2$.

\section{CONTOURS OF WIND PRESSURE COEFFICIENTS ON ROOF AND WALLS OF LOW-RISE BUILDINGS}

Based on the wind tunnel test data, contours of mean, maximum, minimum and RMS values of wind pressure coefficients on the roof and walls, calculated with Equation (1 4), were drawn as shown in Figure 4. Most of the contours are disclosed on the website mentioned on context.

Figure 4 shows two of the contours. It can be seen that, although there are some differences among the wind pressure coefficients at different locations, the mean pressure coefficients near the ridge for wind parallel to the ridge and those on the center-line of the roof for wind perpendicular to the ridge represent approximately the wind pressure coefficients on the whole roof. 


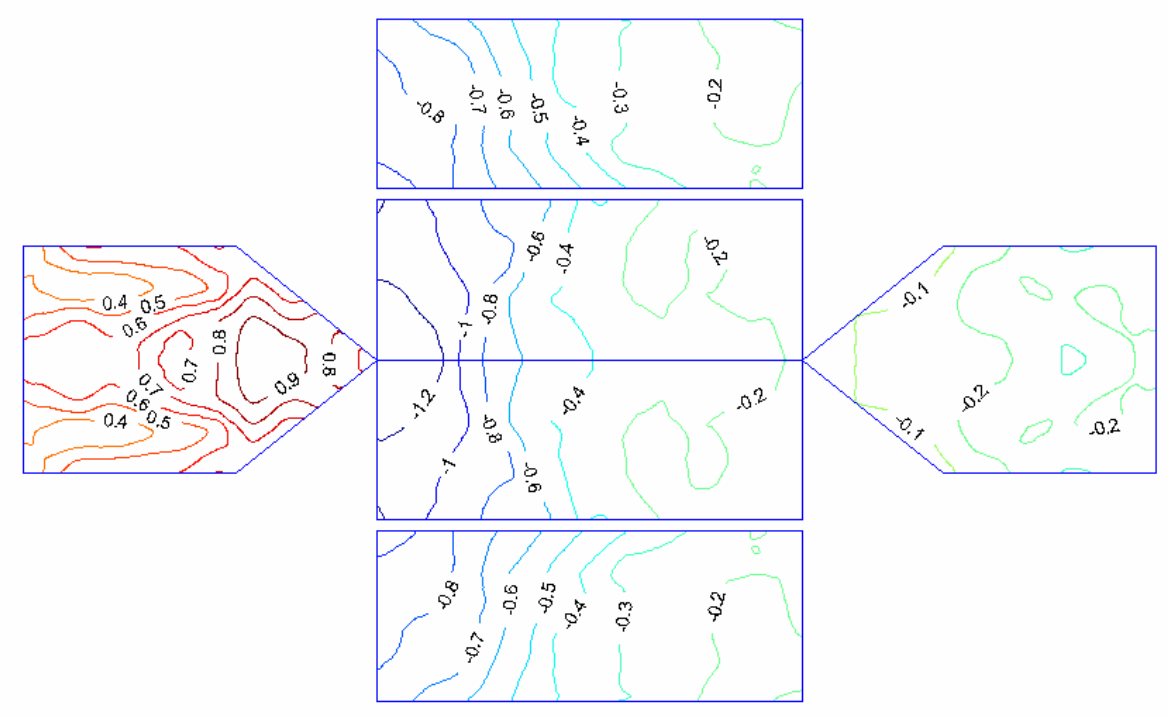

Average Wind Pressure Coefficients of Model Case 13 Height $=120 \mathrm{~mm}$, Breadth $=160 \mathrm{~mm}$, Depth $=240 \mathrm{~mm}$, Roof Pitch $=45^{\circ}$, Wind Direction Angle $=0^{\circ}$

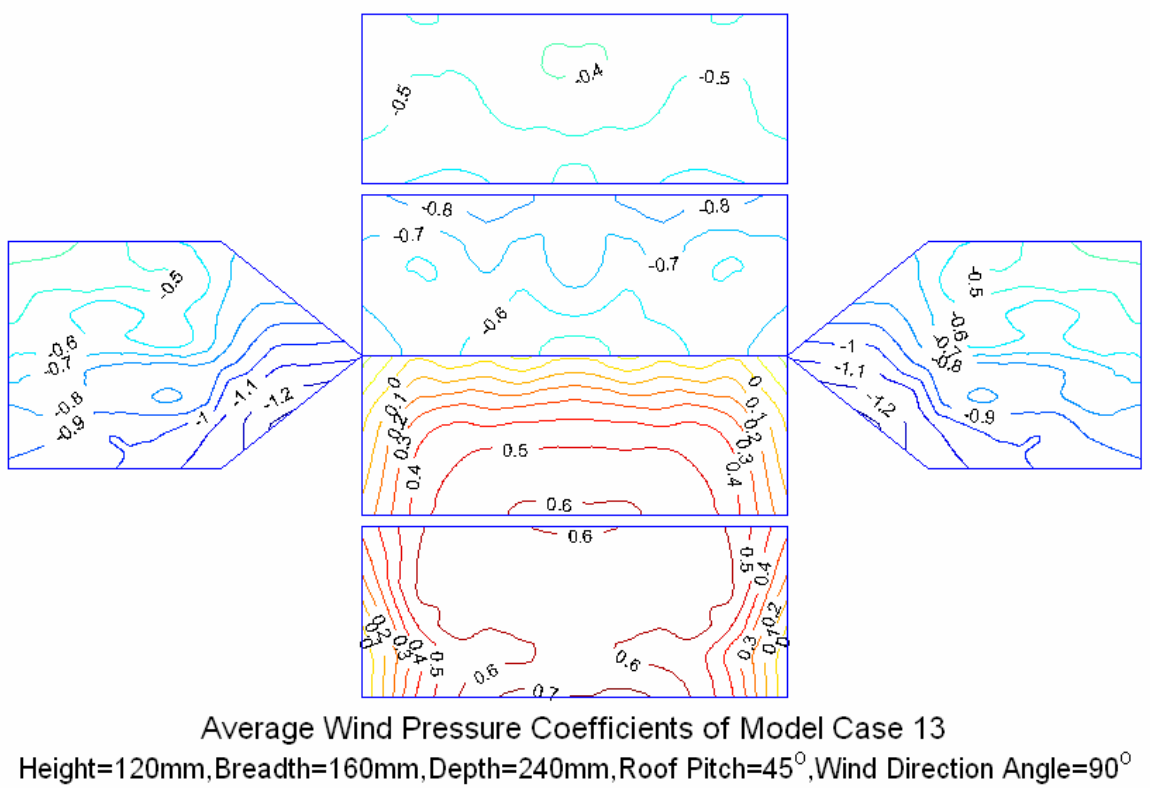

Figure 4. Contours of Mean Wind Pressure Coefficients on Roof and Wall of Low-rise Buildings

The following paragraphs focus on the mean wind pressure coefficients on gable roofs for wind parallel or perpendicular to the ridge.

\section{COMPARISION WITH TEST RESULTS IN LITERATURE}

In order to verify the validity of present test data, the values of $\bar{C}_{p}$ on the centerline of several gable roofs with wind direction angles of $90^{\circ}$ gotten from present wind tunnel tests are chosen to compare with those shown in Holmes' book [1] and Meecham's paper [11] shown in Figure 5. 


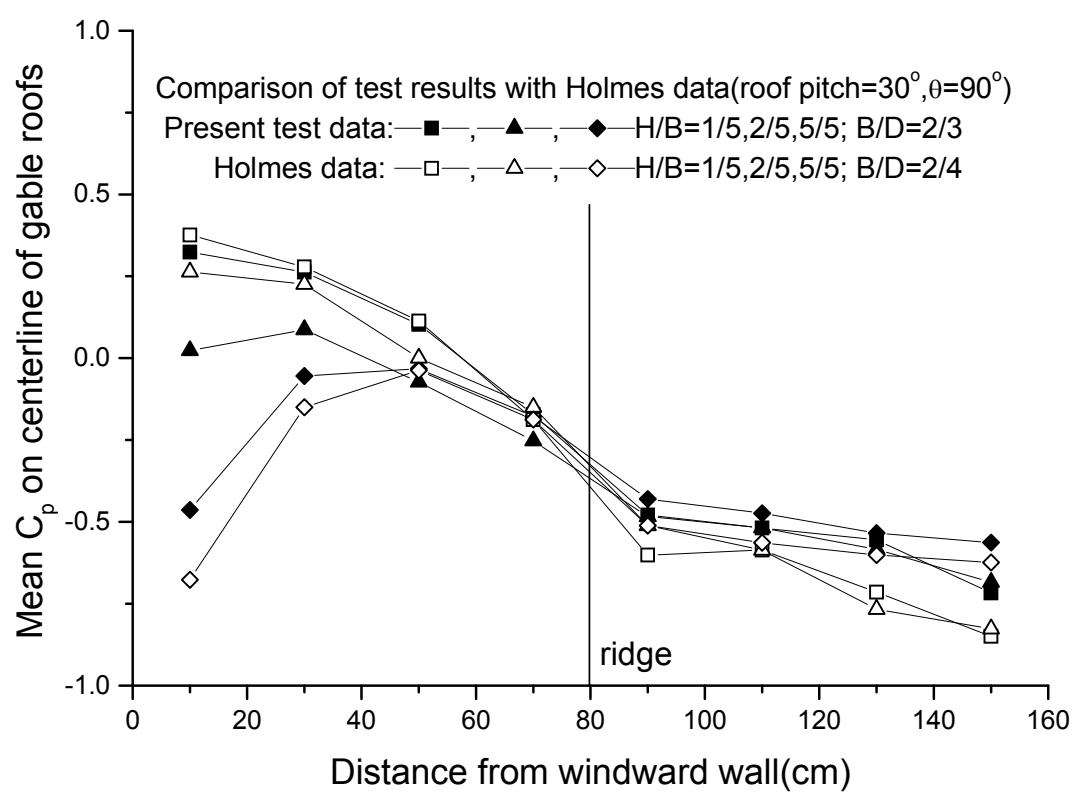

(1)

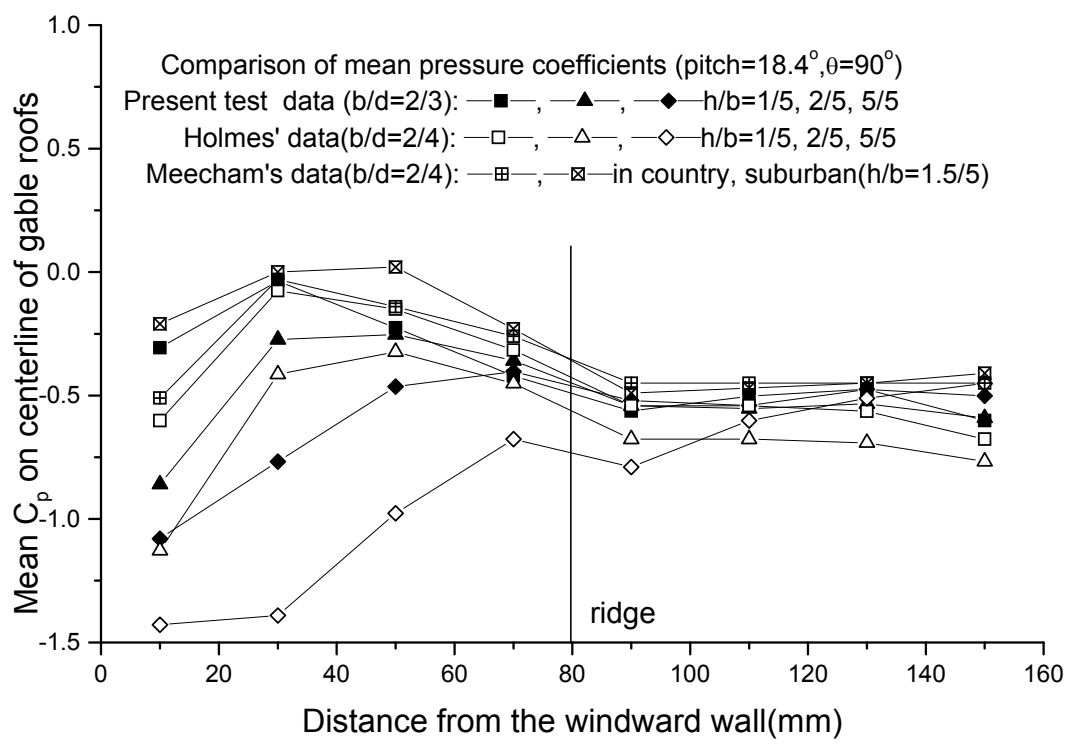

(2)

Figure 5. Comparison of Wind Pressure Coefficients on Gable Roofs

In Figure 5, the trend of the mean wind pressure coefficients obtained from different wind tunnel tests is similar, while there are some differences between the present test data and those of Holmes, especially for the model with a height/breadth ratio of $5 / 5$ and a roof pitch of 18.4 , as shown in Figure 5 (2). These differences should be induced by the differences between the test models and wind fields in these two wind tunnel tests. The breadth/depth ratio of Holmes' testing model was $2 / 4$ while the present one is $2 / 3$. The test data of Meecham are a little different from the present ones, since the breadth/depth ratio of Meecham's testing model was $2 / 4$ and the height/breadth ratio was $1.5 / 5$, which is not exactly the same absolutely as the present ones. Furthermore, the turbulence intensities at mid-height of the gable roofs in Meecham's test were 0.14 and 0.18 , respectively, while that of the present one is about 0.25 . 


\section{MEAN WIND PRESSURE COEFFICIENTS FOR WIND PARALLEL OR PERPENDICULAR TO ROOF RIDGES}

The temporal mean wind pressure coefficients, $\bar{C}_{p}$, at each test points on the roofs are calculated from present wind tunnel test data. Effects of roof pitch, building height and building depth on these mean wind pressure coefficients are analyzed in the following paragraph.

\subsection{When Wind Direction Angle is 90}

Figure 6 shows $\bar{C}_{p}$ on the gable roof for different roof pitches, $\beta . \bar{C}_{p}$ on the windward roof increases with increasing $\beta . \bar{C}_{p}$ near the windward eave is about -1.5 for $\beta \leq 4.8^{\circ}$ and increases with increasing $\beta$. When $\beta$ is larger than $30^{\circ}$, positive values of $\bar{C}_{p}$ begin to appear on the windward roof. When $\beta=45^{\circ}, \bar{C}_{p}$ near the windward eave is +0.6 . On the leeward roof, $\bar{C}_{p}$ is $-0.7 \sim-0.3$ and decreases with increasing roof pitch, while those near the ridge are around -0.6 and are hardly affected by the roof pitch.

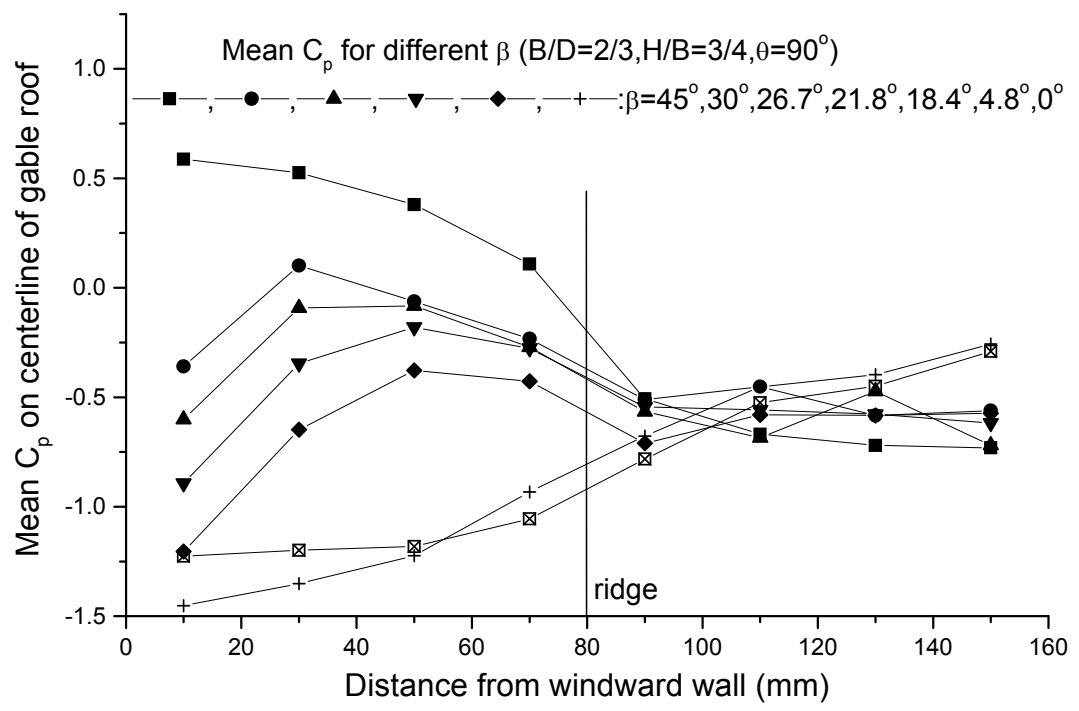

Figure 6. $\bar{C}_{p}$ on Gable Roofs for Different Roof Pitches When Wind Flows Across Roof Ridge

More test results show that for a wind direction angle of $90^{\circ}, \bar{C}_{p}$ on the windward gable roof with a roof pitch larger than $18.4^{\circ}$ can be considered as linear functions of roof pitch.

Figure 7 shows $\bar{C}_{p}$ for different model heights. For $\beta=26.7^{\circ}, \bar{C}_{p}$ on the windward roof are mostly negative for $H / B=3 / 8 \sim 18 / 8$ and the suction pressure coefficient increases with increasing height/breadth ratio. This is surprising. With increasing height/breadth ratio, it becomes difficult for the flow to make a detour across the gable roof. More and more flow should make a detour around the sidewalls. This should make the suction pressure coefficients on the windward roof small. However, the present test results show the opposite effect. The test results in Holmes' book showed the same trend. 


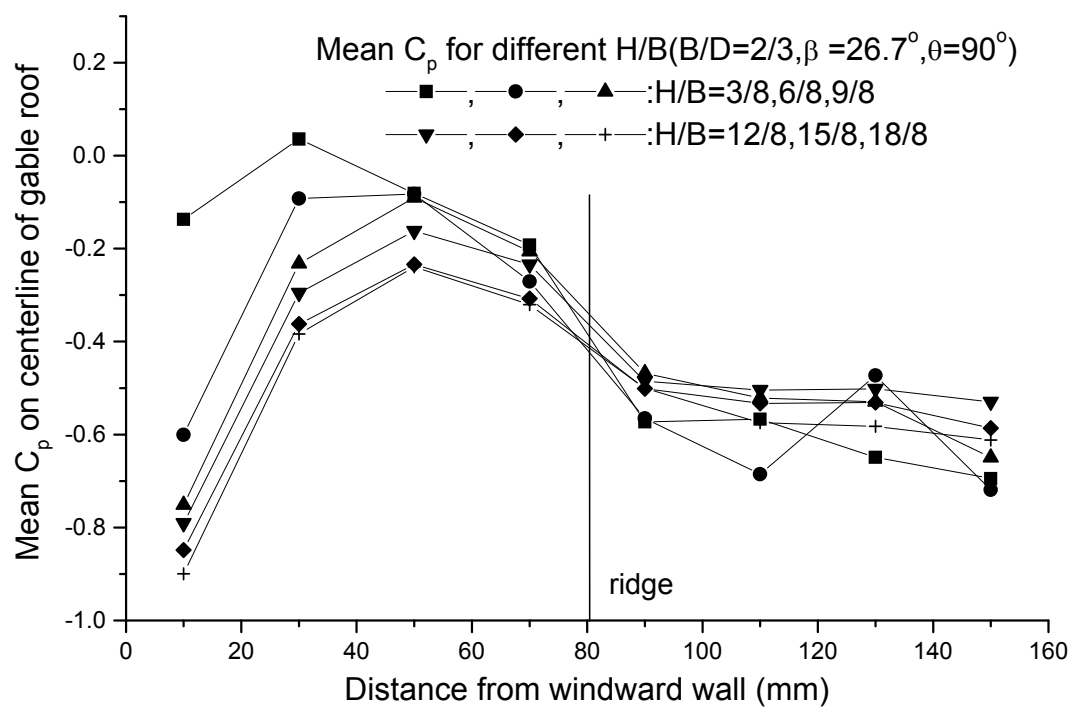

Figure 7. $\bar{C}_{p}$ on Gable Roofs for Different Building Heights When Wind Flows Across Roof Ridge

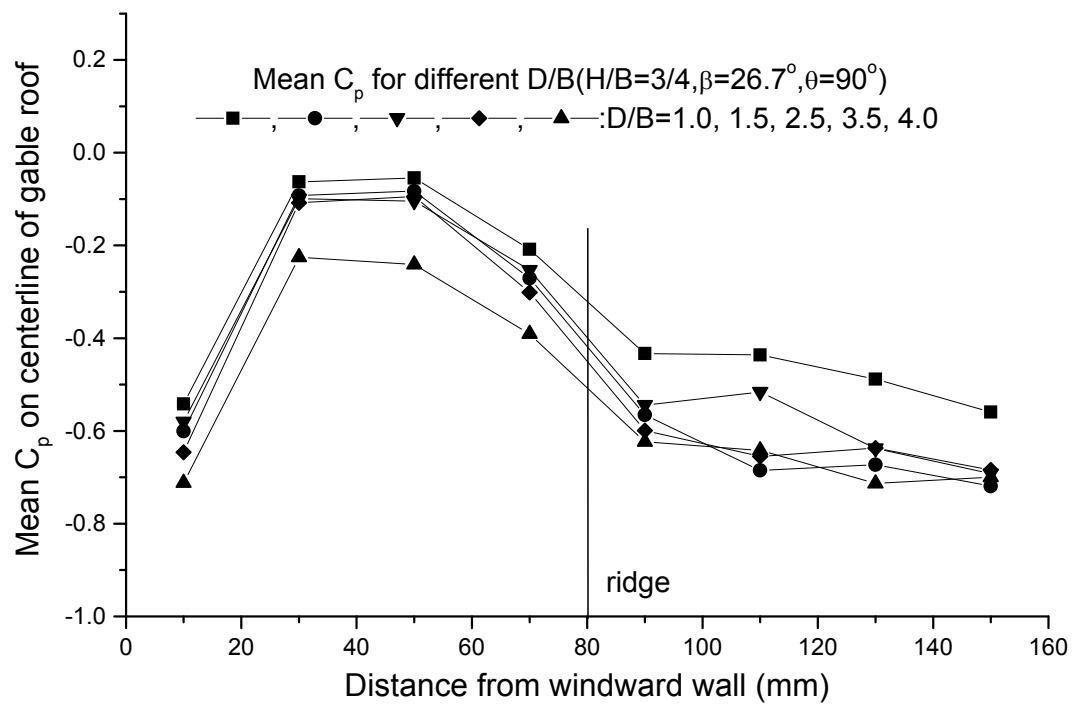

Figure 8. $\bar{C}_{p}$ on Gable Roofs for Different Building Depths When Wind Flows Across Roof Ridge

More test data indicate that $\bar{C}_{p}$ near the leeward eave of the steep gable roof increase slightly with increasing model height and those near the ridge show no obvious trend. However, for the gable roof with a roof pitch of $4.8^{\circ}$ and the flat roof, $\bar{C}_{p}$ on the whole roof decrease with increasing model height except those near the windward eave, which are fixed at about -1.2 regardless of the model height.

Figure 8 shows $\bar{C}_{p}$ on the gable roof for different depth/breadth ratios when the wind direction angle is $90^{\circ}$. As shown, with increasing depth/breadth ratio, $\bar{C}_{p}$ on the whole roof decreases. With increasing depth/breadth ratio, it becomes difficult for the flow to make a detour around the sidewalls and more and more flow should make a detour across the gable roof. This makes the suction pressure coefficients on the roof large. The present test results confirmed this conclusion. 


\subsection{When Wind Direction Angle is $0^{\circ}$}

When the wind direction angle is $0^{\circ}, \bar{C}_{p}$ on the whole roof is negative and increases with increasing distance from the measured point to the windward gable wall. When this distance reaches the house breadth, $\bar{C}_{p}$ become fixed at about -0.15 and do not increase any more.

Figures 9 11 show $\bar{C}_{p}$ for different roof pitches, building heights and building depths for a wind direction angle of $0^{\circ}$. It can be seen that the roof pitch, height/breadth ratio and depth/breadth ratio have little effect on $\bar{C}_{p}$ when wind flows along the roof ridge.

\subsubsection{Fitted equations of mean wind pressure coefficient}

Based on the test data of mean wind pressure coefficients on the gable roof, following equations are fitted.

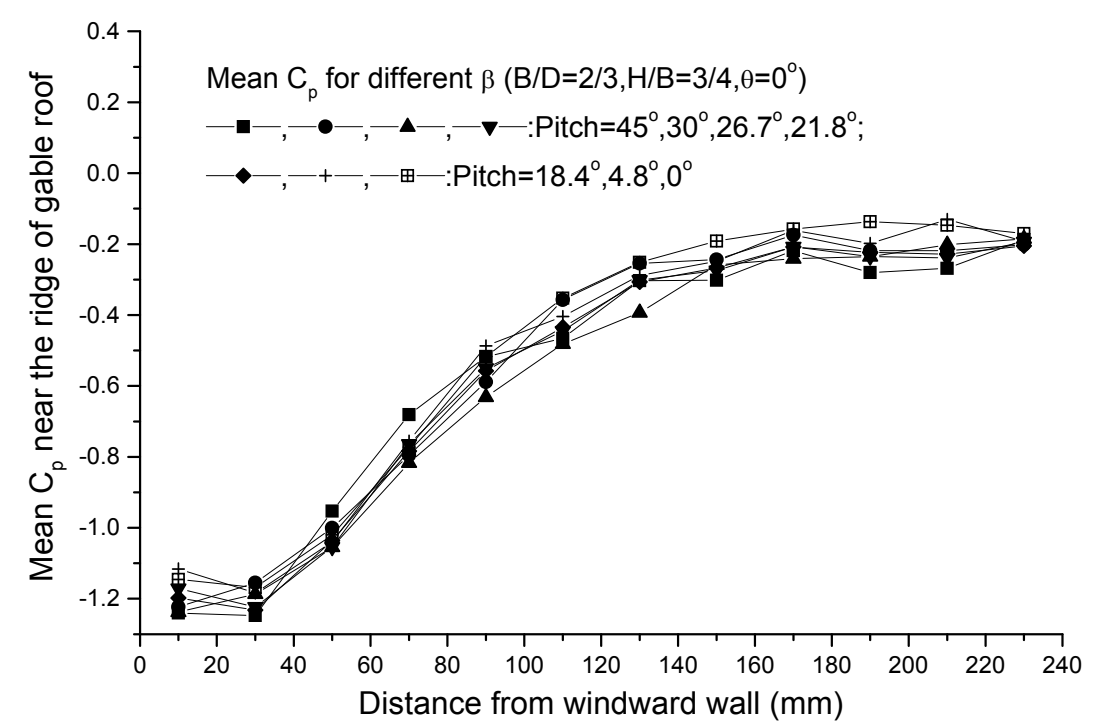

Figure 9. $\bar{C}_{p}$ on Gable Roofs for Different Roof Pitches When Wind Flows Along Roof Ridge 


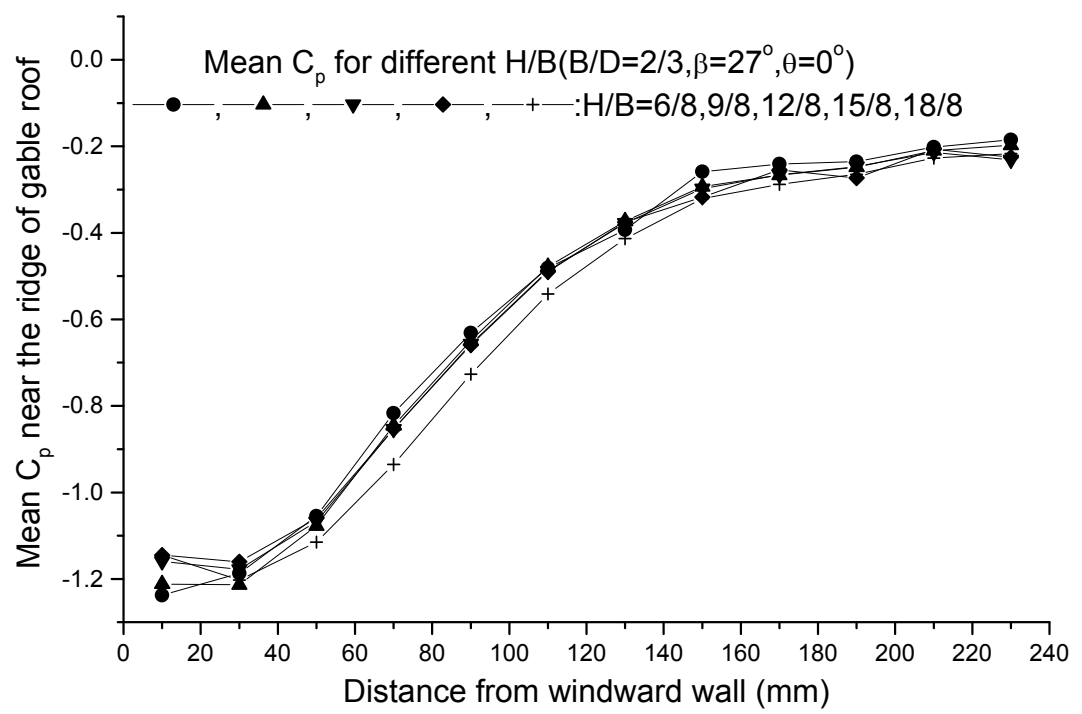

Figure 10. $\bar{C}_{p}$ on Gable Roofs for Different Building Heights When Wind Flows Along Roof Ridge

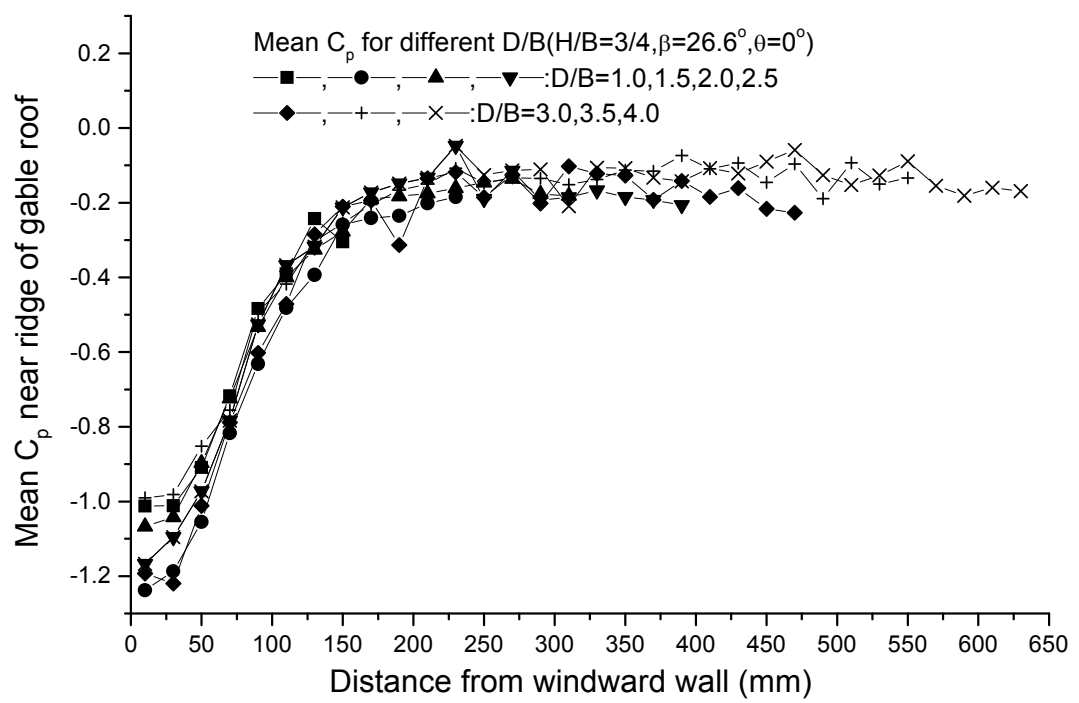

Figure 11. $\bar{C}_{p}$ on Gable Roofs for Different Building Depths When Wind Flows Along Roof Ridge

When the wind direction angle is $90^{\circ}, \bar{C}_{p}$ on a roof with pitches of $18.4^{\circ} \sim 45^{\circ}$ can be calculated by the following fitted equation:

$$
\begin{aligned}
\bar{C}_{p}= & \left\{\begin{array}{l}
\psi_{1}+\psi_{2}\left(b_{1} / B\right)+\psi_{3}\left(b_{1} / B\right)^{2}+0.1-0.05(D / B) \text { for windward roof } \\
-0.3-0.3(b / B)-0.04(D / B) \\
\text { for leeward roof }
\end{array}\right. \\
& \psi_{1}=(3.56-0.094 \beta)(-1.23+0.3(B / H)) \\
& \psi_{2}=\left(8.45+0.4 \beta-0.00127 \beta^{2}\right)\left(0.58+0.12(B / H)-0.066(B / H)^{2}\right) \\
& \psi_{3}=\left(2.4-1.03 \beta+0.02 \beta^{2}\right)\left(0.82+0.3(B / H)-0.125(B / H)^{2}\right)
\end{aligned}
$$

in which, $b$ is the distance from the measured point to the windward sidewall. 
When the wind direction angle is $0^{\circ}$, the value of $\bar{C}_{p}$ on the roof can be calculated by the following approximate equation:

$\bar{C}_{p}= \begin{cases}-1.2+1.05(d / B) & \text { if } d / B<1 \\ -0.15 & \text { if } d / B \geq 1\end{cases}$

in which $\mathrm{d}$ is the distance from the measured point to the windward gable wall.

Compared with the testing data, the mean and maximum error of Equation (5\&6) are about 0.05 and 0.24 , respectively. The $95 \%$ confidence intervals of the calculated results with Equation (5\&6) are \pm 0.2 as shown in Figure 12 .

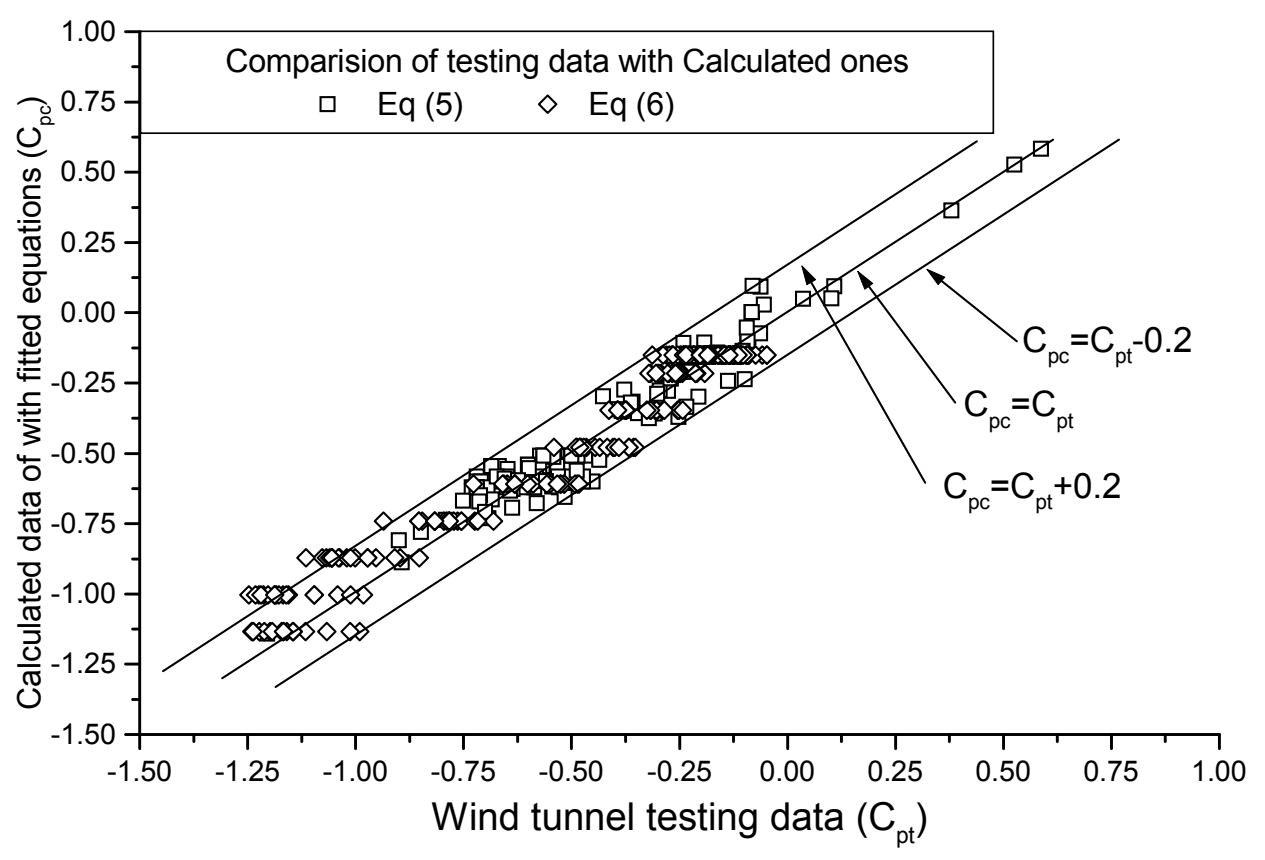

Figure 12. Analysis of Errors of Equation (5\&6)

Figures 13 16 compare data obtained from Equation (5\&6), present test data and data calculated from AIJ Recommendations for Loads on Buildings [10].

In Figure 13, for roof pitches large than $18.4^{\circ}$, the three sets of data, present test data, calculated ones with Equation (5) and calculated ones basing on AIJ [10], show little difference. Only for roof pitches less than $4.8^{\circ}$, the wind suction pressure coefficients on the windward roof calculated from AIJ [10] are smaller than the present test data. 


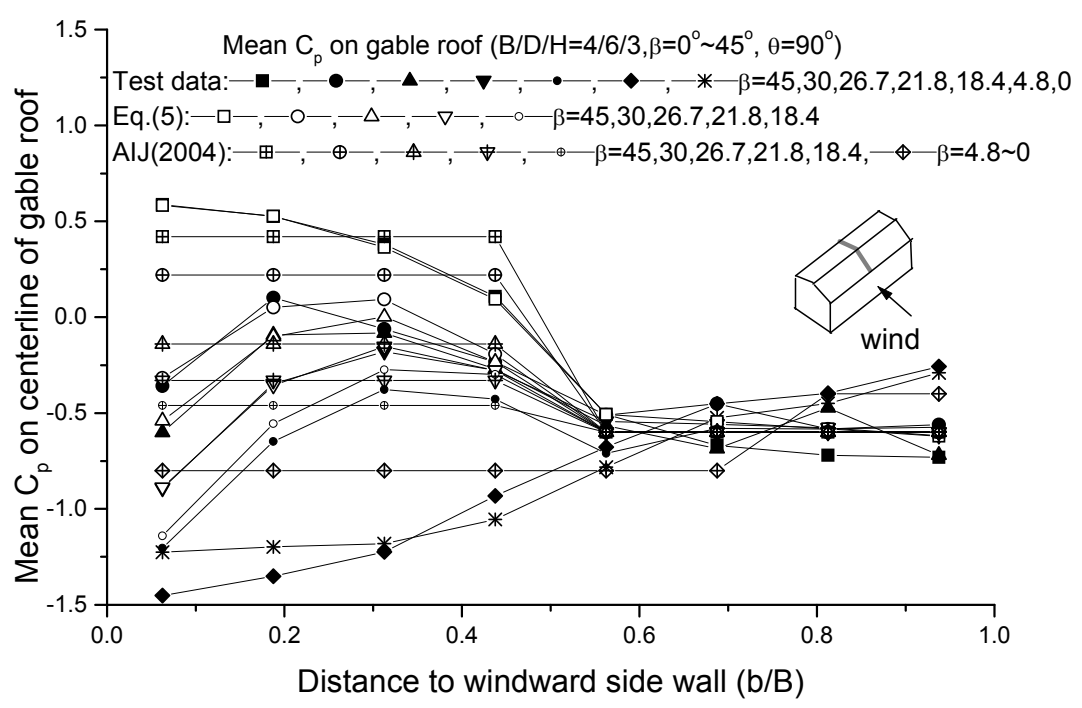

Figure 13. Comparison of Equation (5) with Test Results and Literature for Different Roof Pitch

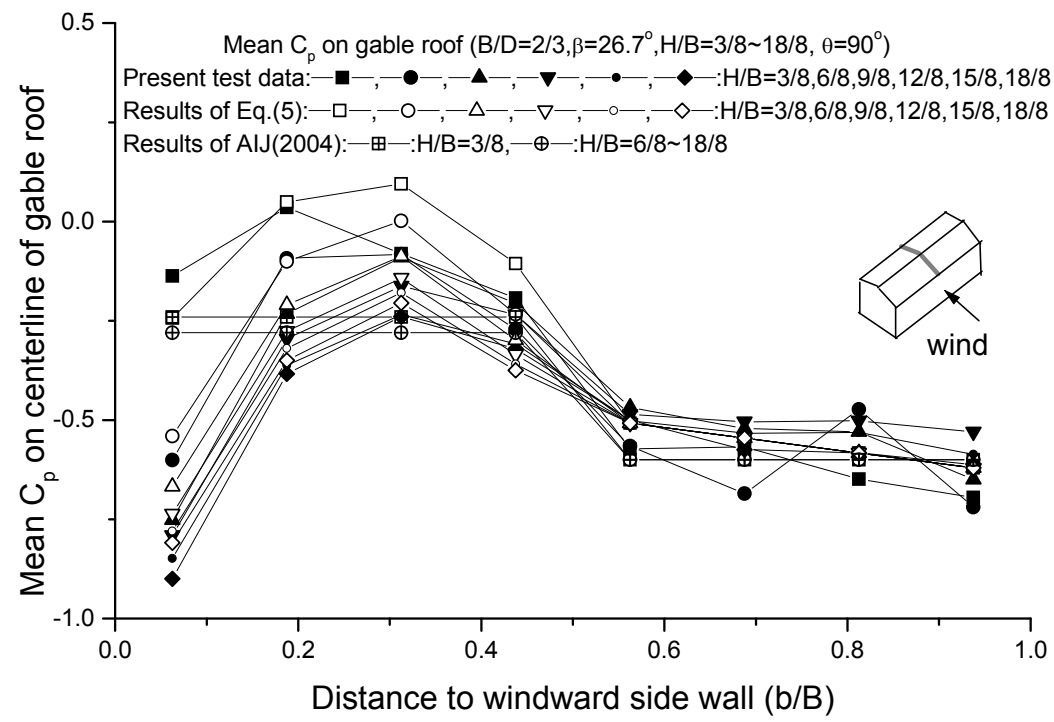

Figure 14. Comparison of Equation (5) with Test Results and Literature for Different Model Height

In Figure 14, the wind pressure coefficients on the windward roof calculated from AIJ [10] vary little with increasing building height, while the present ones decrease with increasing building height. The AIJ [10] method overestimates wind suction pressure on the windward roof for lower buildings and underestimates for higher ones.

Figure 15 shows little difference between present test data and those based on AIJ [10] in most cases, while Equation (5) shows a greater variety of wind pressure coefficients on the roof than the standard. 


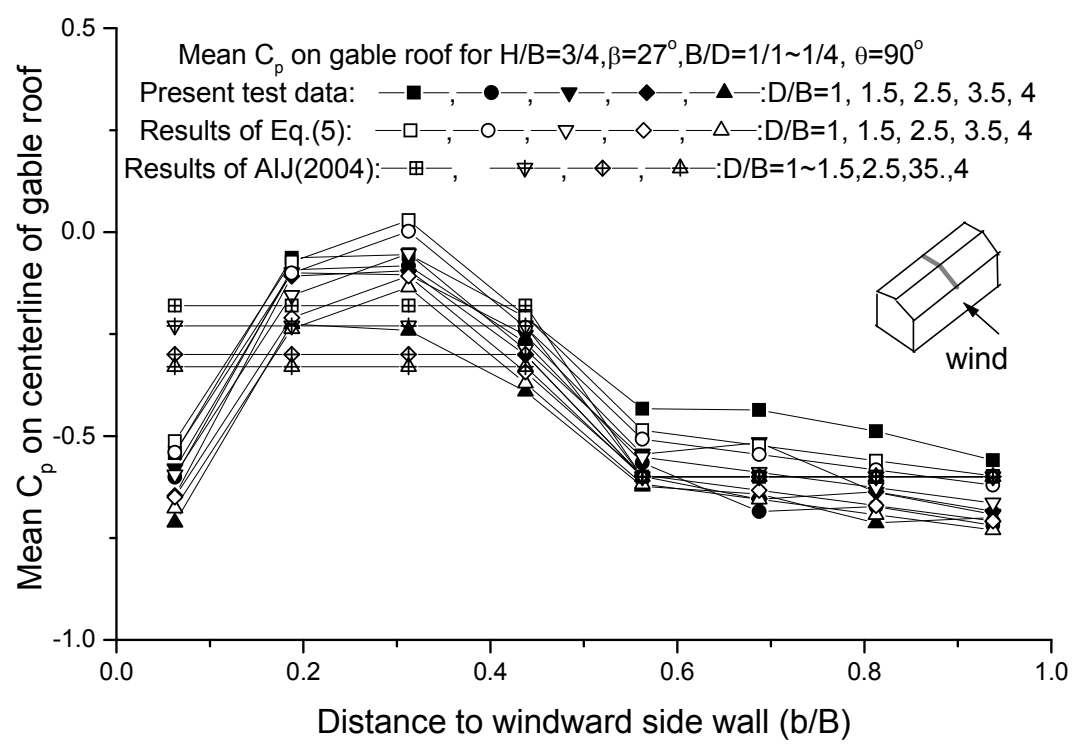

Figure 15. Comparison of Equation (5) with Test Results and Literature for Different Model Depth

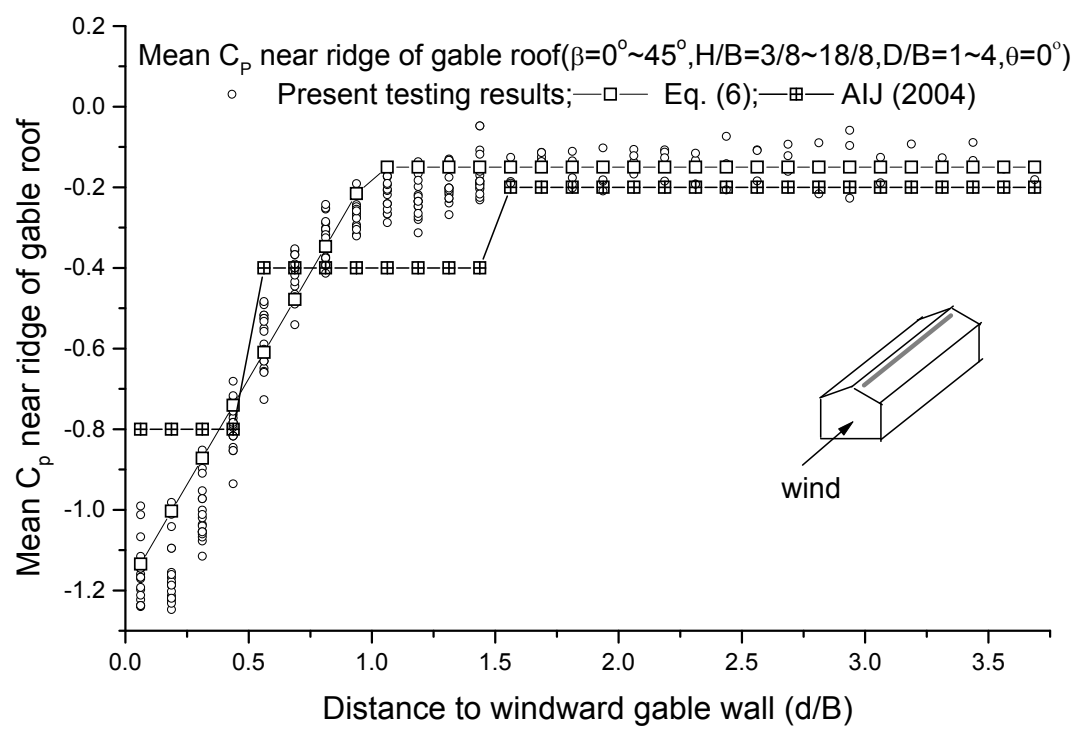

Figure 16. Comparison of Equation (6) with Test Results and Literature

Figure 16 shows that, near the windward wall, the suction wind pressure coefficients in the present test data are larger than those based on AIJ [10]. These differences may be induced by the difference in turbulence intensity. The turbulence intensity at roof height in the present study is about 0.25 , while those in some referenced papers (7 9) of AIJ [10] are $0.11 \sim 0.17$, which are lower than present one. To the rearward, the values given by Equation (6) match quite well with those given by the standard.

It is must be emphasized that Equation (5\&6) are fitted with the wind tunnel test data of gable roofed low-rise buildings with a roof pitch of $18.4^{\circ} \sim 45^{\circ}$, a height/breadth ratio of 3/8 18/8 and a depth/breadth ratio of $1 \sim 4$ in a suburban wind field. For other buildings with geometric parameters different from the present ones in different wind fields, the equations may not yield correct results. 


\section{CONCLUDING REMARKS}

Wind pressures on the roofs of 30 models of gable or hip-roofed low-rise buildings with roof pitches of $0^{\circ} \sim 45^{\circ}$, height/breadth ratios of $3 / 8 \sim 18 / 8$ and depth/breadth ratios of $1.0 \sim 4.0$, were measured in a simulated wind field of suburban terrain. A database of wind loads on the roofs and walls of low-rise buildings is made from results of this wind tunnel test and the contours of the wind pressure coefficients are disclosed on a website.

Mean wind pressure coefficients on gable roofs for wind direction angles of $0^{\circ}$ and $90^{\circ}$ were analyzed. When wind flowed across the roof ridge, with increasing roof pitch, $\bar{C}_{p}$ on the windward roof increased while those on the leeward roof were fixed at about -0.6 regardless of roof pitch. $\bar{C}_{p}$ on windward gable roofs with a roof pitch large than $18.4 \mathrm{o}$ can be considered as linear functions of roof pitch. With increasing height/breadth ratio, $\bar{C}_{p}$ on the windward roof decreased, while that on the leeward roof was affected little by the height/breadth ratio. $\bar{C}_{p}$ on the whole roof decreased with increasing depth/breadth ratio. When wind flowed along the roof ridge, $\bar{C}_{p}$ was negative and increased along the wind direction. When the distance from the windward gable end to the measured point was larger than the house breadth, $\bar{C}_{p}$ did not increase any more and remained fixed at about -0.15 . In this condition, $\bar{C}_{p}$ on the whole roof was hardly affected by roof pitch, house height or house depth.

Based on the analysis, two new equations for calculating wind pressure coefficients on gable roofs for wind flowing along or across the roof ridge were fitted. The equations fitted well with present test data, which were close to data from Holmes' book. However, there were some differences between the present data those calculated from the standard. These differences may have been induced by the different turbulence intensity of the testing wind field. The fitted equations show more variety of wind pressure coefficients on the roof than the standard.

\section{ACKNOWLEDGEMENTS}

This study was funded by the Ministry of Education, Culture, Sports, Science and Technology, Japan, through the 21st Century Center of Excellence Program, 2003-2007, which is gratefully acknowledged.

\section{REFERENCES}

[1] Holmes, J.D., "Wind Loading of Structures", Spon Press, London, UK, 2001.

[2] Uematsu, Y. and Isyumov, N., "Wind Pressures Acting on Low-rise Buildings", Journal of Wind Engineering \& Industry Aerodynamics, 1999, Vol. 82, pp. 1-25.

[3] Stathopoulos, T., "Turbulent Wind Action on Low-rise Buildings", Ph.D Thesis, Faculty of Engineering science, The University of Western Ontario, Canada, 1979.

[4] Stathopoulos, T., Surry, D. and Davenport, A.G., "A Simplified Model of Wind Pressure Coefficients for Low-rise Buildings", Proceedings of ICOSSAR' 85, 1985.

[5] Holmes, J.D., "Wind Pressure and Force on Tropical Houses", Final Report of Project No. 17 of the Australian Housing Research Council, Melbourne, Australia, 1980.

[6] Holmes, J.D., "Wind Pressure on House with High Pitched Roofs", Wind Engineering Report 4/81, James Cook University, Townsville, Australia, 1981. 
[7] Kamei, Y. and Maruta, E., "Wind Tunnel Test Study on Wind Pressure of Gable Roof Buildings, Part 2: Cases With Eaves (in Japanese)", Proceedings of AIJ conference (Structure Construct Engineering), September 1981, pp. 1041-1042.

[8] Ueda, H., Tamura, Y. and Fujii, K., "Effects of Turbulence of Approaching Wind on Mean Wind Pressure Acting on Flat Roofs (in Japanese)", Journal of Structure Construct Engineering, 1991, AIJ, No. 425, July, pp. 91-99.

[9] Maruta, E. et al., "A Study on Wind Pressure Coefficients about Low-rise Buildings with Gable Roofs, Part 3: Mean Wind Pressure Coefficient and Wind Direction (in Japanese)", Proceedings of AIJ conference (B), August 1992, pp. 119-120.

[10] AIJ, "AIJ Recommendations for Loads on Buildings", Architectural Institute of Japan, 2004.

[11] Meecham, D., Surry, D. and Davenport, A.G., "The Magnitude and Distribution of Wind-induced Pressures on Hip and Gable Roofs", Journal of Wind Engineering \& Industry Aerodynamics, 1991, Vol. 38, pp. 257-272. 